L.

\title{
REPORT AND COMMENTS ON TWENTY-SIX CASES OF TONSILLECTOMY, TWO AND A HALF YEARS AFTER OPERATION.*
}

\author{
By At,Fred LEWY, M. D.,
}

\section{Chicago.}

Last winter we undertook to examine a number of patients on whom tonsillectomy had been performed two. and a half or more years before. with a view to ascertaining the permanent results obtained and adding to the sum total of our knowledge concerning the results of this operation. A similar and larger list was published by Clark, of Boston (ANNALS OF Otol.cGr. June, 1913), and altogether his results appear more favorable than ours; but his list being larger, he does not publish his cases in the same detail as is herein observed. These patients were all observed at the Illinois Charitable Eye and Ear Infirmary, on the service of Dr. Norval Pierce, and all but one or two of them were operated there.

Four hundred cards were sent out, as a result of which twenty-four patients reported for examination. Two others, not on the card list, came in for other reasons, and are included in the list below.

The conditions investigated were:

Local.- Remains of adenoid or tonsil tissue. Deformities. Present condition of upper respiratory tract.

General.-Growth and nutrition as compared with other (nonoperated) members of the same family. General health. Tendency to local and systemic infections. Cervical adenitis; goitre; condition of ears.

The results are reported in detail in the following list:

* Read before the Chicago Laryngological and Otological Soclety, March 17, 1914. 
TONSILLECTOMY SEVERAL, YEARS AFTER OPERATION. 593

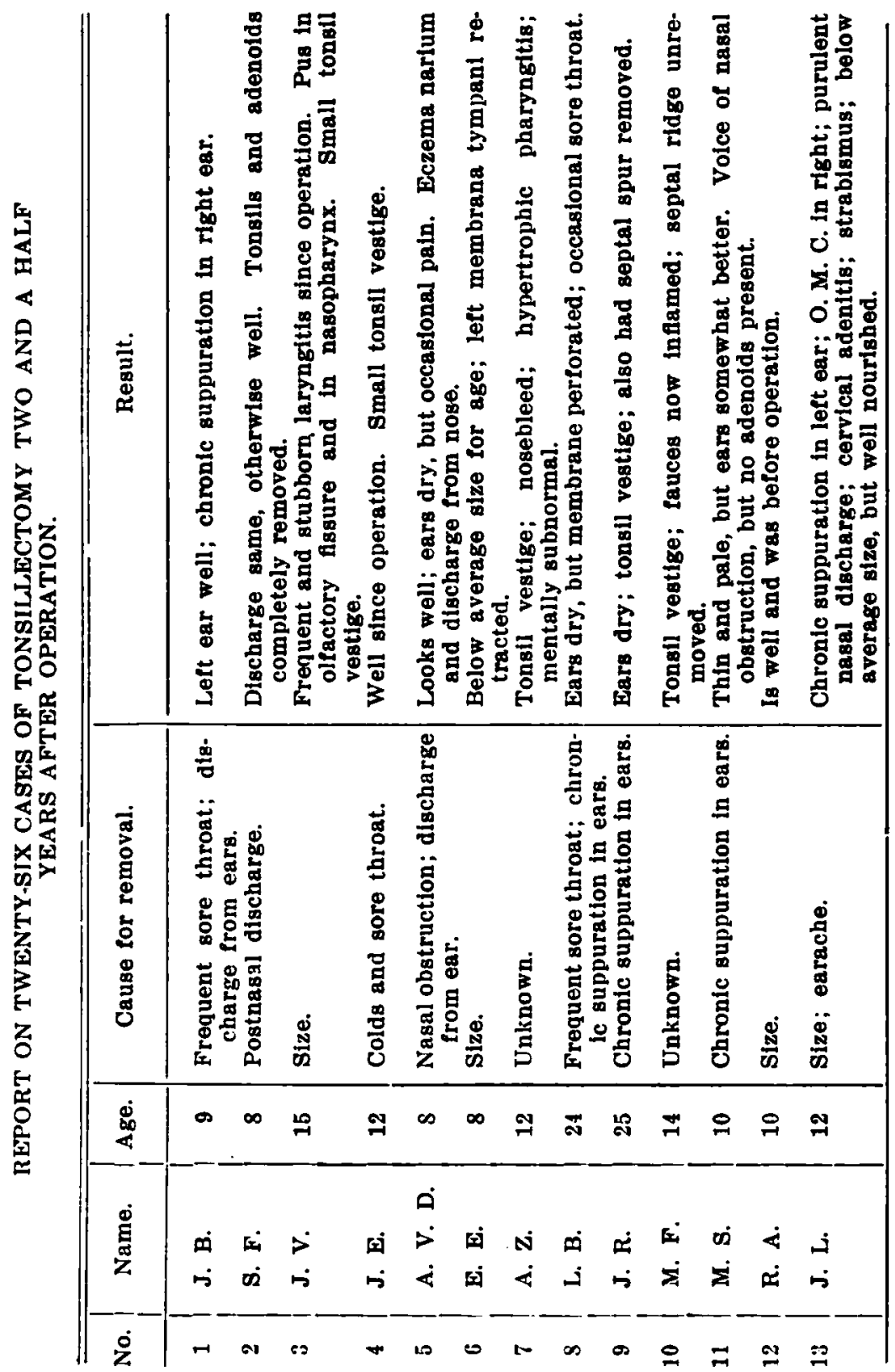




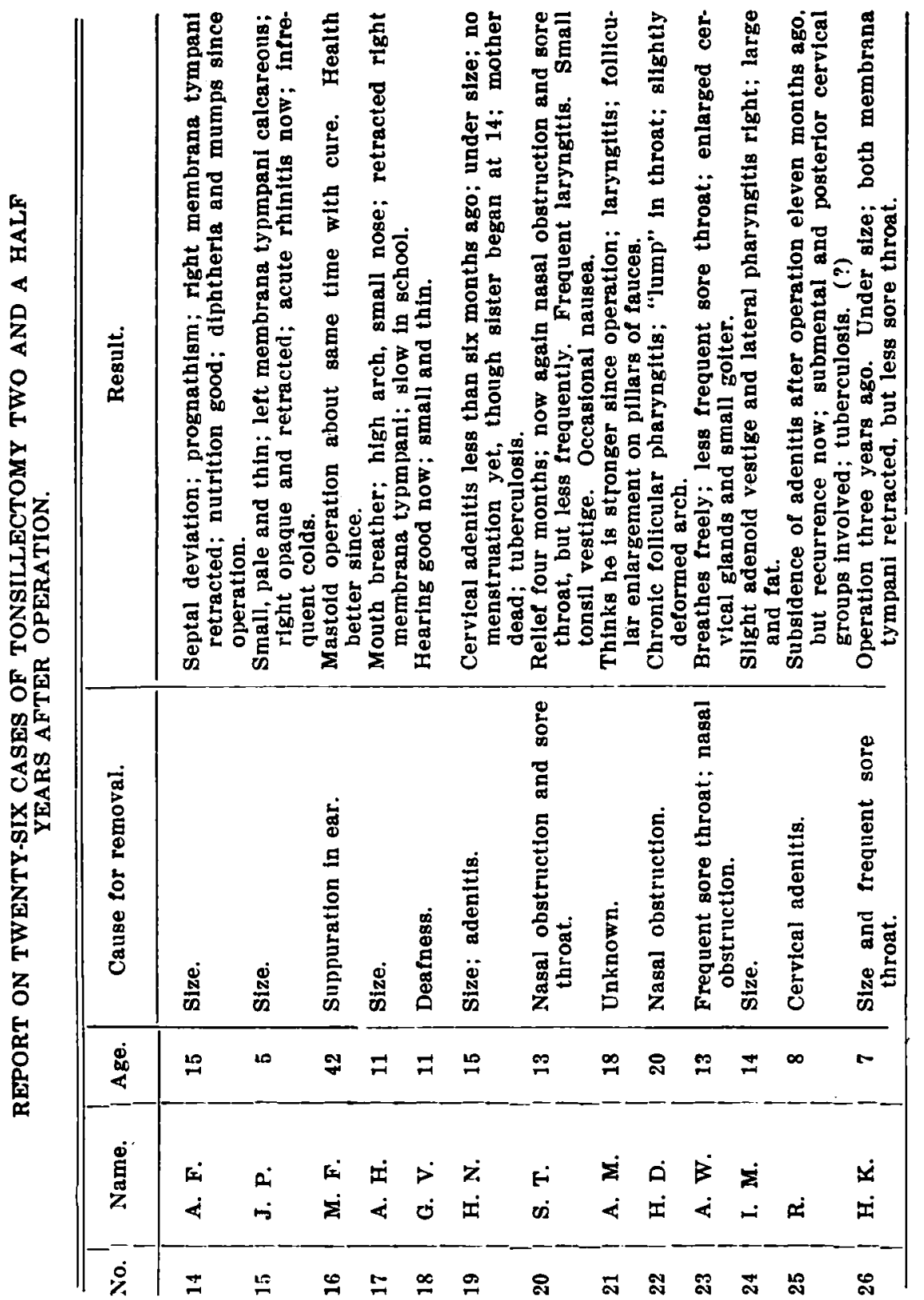




\section{COMMENTS.}

Nine patients, Nos. $1,4,5,8,9,12,16,18$ and 23 , were improved 'or cured of the condition for which the operation was performed. Four of these were operated because of suppurating ears (Nos. 1, 8, 9 and 16), and one, No. 18, for nonsuppurative deafness. 'The improvement in these cases may have been due to the removal of adenoids, which was done at the same time. No. 16 also had a mastoid operation.

Seventeen patients were apparently not benefited. Three, Nos. 3, 20 and 21, are now troubled with laryngitis, which tendency appeared subsequent to the tonsil removal. It is rather difficult to account for this except in the case of No. 3, which shows evidence of sinusitis.

Of five patients under the age of six at the time of operation, three, Nos. 6, 15 and 26 , are undersized. Of the other two who seem to be of good general health and development, No. 2 still has the postnasal discharge which was one of the indications for operation, and No. 5 still has a nasal discharge, although cured of a discharging ear. In neither could sinusitis be demonstrated, nor does either show any tonsil or adenoid vestige.

'There was little to criticise so far as the mechanical part of the surgery was concerned. One patient showed a little asymmetry of the arch. Several showed slight tonsil remains but not of a degree or kind that appeared to be causing any trouble.

The conditions that appear to have been benefited are "frequent sore throat" and "ear troubles." Of course the cases of simple hypertrophy were relieved of the enlargement, but two of these and one other, in children under six, now show evidence of retarded growth; whether due to the removal of tonsils or not we cannot say. Only one child gave a history of infectious disease since the operation, but many of the patients are of an age when the diseases of childhood are no longer common. In none of the cases do we get any light on the subject of the relation of the tonsils to arthritis or other systemic infections.

Twenty-six cases are too few from which to draw any definite general conclusions: however, we must admit that so far as this list is concerned the results obtained did not justify 
the operation in seventeen out of the twenty-six. I believe our indications for operation are as conservative as those of any clinic in Chicago, but we now restrict still further our indications for tonsillectomy. In children before the age of the second dentition I believe we should perform a tonsillotomy for simple hypertrophy, or wherever possible confine ourselves to removal of the adenoid hypertrophy. This of course does not apply to cases where the tonsils are removed because they are manifestly diseased or for systemic conditions. 'There are few operations attended by more gratifying results than is tonsillectomy in properly selected cases. 'The above list suggests that we still have something to learn about the proper selection of cases. I do not think the removal of tonsils is indicated in the absence of direct evidence of their causal relation to the condition for which relief is rought, that is, on suspicion, except perhaps in the case of certain systemic infections (arthritis, etc.), in which diligent search by competent men has failed to reveal any other source of infection or portal of entry, and in which other systematic treatment has failed. 